\title{
Principales causas de mortalidad de las compañías de comercio en la región central de Ecuador $^{1}$
}

\section{Main Causes Of Mortality Of Companies In Central Region Of Ecuador}

\author{
Jorge Vladimir Núñez Grijalva ${ }^{2}$ \\ Verónica Leonor Peñaloza López 3 \\ Edwin José Armijos Velasco ${ }^{4}$
}

\section{RESUMEN}

La mayor parte de los estudios referentes a las compañías de comercio, abordan los aspectos relativos a la etapa inicial en la vida de estas, como es su etapa de

1 Fecha de recepción: 4 de junio de 2015. Fecha de aceptación: 14 de diciembre de 2015. Para citar el artículo: Nuñez, J., Peñaloza, V. y Armijos, E. "Principales causas de mortalidad de las compañías de comercio en la región central de Ecuador". Revist@ E-Mercatoria, vol. 14, No2, julio - diciembre, 2015. DOI: https://doi.org/10.18601/16923960.v14n2.03

2 Magister en Economía y Derecho del Consumo, Universidad de Castilla-La Mancha; Magister en Derecho Administrativo, Universidad Técnica Particular de Loja, Magister en Gestión Estratégica Empresarial, Universidad Técnica de Ambato; Abogado, Universidad Nacional de Loja ${ }_{i}$ Ing. de Empresas, Universidad Técnica de Ambato ${ }_{i}$ Docente Universitario Pontificia Universidad Católica del Ecuador Sede Ambato; Ambato, Ecuador; inunez@ pucesa.edu.ec

3 Magister en Tributación y Derecho Empresarial Universidad Técnica de Ambato ${ }_{i}$ Ingeniera en Contabilidad y Auditora CPA Universidad Técnica de Ambato; Docente Universitaria Pontificia Universidad Católica del Ecuador Sede Ambato; Ambato, Ecuador; vpenaloza@ pucesa.edu.ec

4 Master en Dirección y Gestión Turística Universidad Autónoma de Barcelona; Ingeniero Comercial con mención en Administración Pontificia Universidad Católica del Ecuador, Licenciado en Administración Pontificia Universidad Católica del Ecuador; Docente Universitario Pontificia Universidad Católica del Ecuador Sede Ambato; Ambato, Ecuador; earmijos@pucesa.edu.ec 
constitución. Sin embargo, muy pocos estudios han analizado la etapa final de una compañía y especialmente, las causas que provocan su mortalidad y cierre. El presente artículo pretende analizar las principales causas de mortalidad de las compañías de comercio, desde tres ámbitos diversos y complementarios a la vez: legal, administrativo y contable-financiero, en las sociedades mercantiles de la Región Central de Ecuador. Esta investigación proporciona una síntesis de las principales causas de mortalidad, las cuales deberían ser consideradas por los actuales y futuros empresarios, con el objeto de fortalecer sus decisiones relativas a la supervivencia de las compañías.

Palabras Claves: Compañía, Control Interno, Cultura Tributaria, Disolución, Proceso Administrativo.

\section{ABSTRACT}

Most of the studies concerning trading companies, addressing aspects of the initial stage in the life of these, such as its formation stage. However, few studies have examined the final stage of a company and especially the causes of mortality and closing. This article analyzes the main causes of mortality trading companies from three different and complementary disciplines at once: legal, administrative and financial accounting in commercial companies of the Central Region of Ecuador. This research provides a summary of the major causes of mortality, which should be considered by the current and future employers, in order to strengthen their decisions regarding the survival of companies.

Key Words: Company, Internal Control, Tax Culture, Dissolution, Administrative Process.

\section{INTRODUCCIÓN}

Durante la última década ha sido notable el volumen de nuevas compañías de comercio en Ecuador y en particular en la Región Central del país; sin embargo, no se han realizado estudios sobre la mortalidad de las mismas, por lo que el presente trabajo constituye un aporte en este campo.

Se tuvo como objetivo analizar las principales causas que generan mortalidad en las compañías de comercio en la región central (Tungurahua, Cotopaxi y Chimborazo). Se aborda el tema desde un punto de vista holístico al interior de una empresa, considerando los tres principales ámbitos que tienen incidencia directa en la toma de decisiones que podrían, en casos determinados, conllevar a la mortalidad de la misma; estos ámbitos son el Jurídico, Administrativo y Contable-Financiero.

Por lo expuesto, la decisión de cierre de una compañía, tiene como elemento central el proceso de toma de decisiones que sobre ellas realiza el empresa- 
rio y sus socios, en todos los diversos campos relacionados al negocio, como pueden ser: la administración, el mercado, las finanzas, los recursos humanos y el cumplimiento de la normativa legal vigente y exigible en el campo societario, tributario o laboral ${ }_{i}$ el nacimiento, desarrollo y madurez exitosa o el fracaso y cierre de una compañía, son resultado en gran medida de la calidad de decisiones adoptadas por el empresario y sus socios.

Se investigaron las consecuencias generadas en los tres ámbitos propuestos, las cuales conllevan a la ejecución del procedimiento administrativo para el cierre de las compañías, aplicado en base a la normativa legal vigente (ver Nota 1). Esto se complementó con el análisis comparativo de la situación pertinente de Colombia, mediante el estudio del Código de Comercio (1971); y en Perú, mediante el estudio de la Ley General de Sociedades (1997).

Los resultados del estudio serán un aporte para disminuir la mortalidad en las compañías, ayudando a proteger de esta manera la actividad empresarial, las fuentes de empleo y, en términos generales, colaborando al desarrollo social y económico de la Región.

El presente artículo tiene la siguiente estructura:

En la Sección 1, Introducción; en la Sección 2, Antecedentes; en la Sección 3, Metodología ${ }_{i}$ en la Sección 4, Resultados de la Investigación; en la Sección 5, Análisis Comparado de la Situación Pertinente en Colombia y Perú, en la sección 6, Análisis de dos Casos de Ejemplo, de Compañías Ecuatorianas Canceladas, en la Región Central del País $;$ y finalmente, en la sección 8 , Conclusiones.

\section{DESARROLLO DEL ARTÍCULO}

\subsection{Aporte Cientifico}

En nuestro país, existen dos estudios previos y similares al presente: i) en la Región Central del país, el estudio de Montenegro (2012), denominado Diseño de un Manual de Lineamientos para Disminuir la Mortalidad en las Compañias de Nueva Creación en la Intendencia de Compañias de Ambato_efectuado como tesis de pre-grado en la PUCESA, el cual es un análisis de las acciones gerenciales, por acción (toma errónea de decisiones) u omisión (falta de decisiones), que conllevan a la mortalidad empresarial. Por otro lado, se realiza un análisis general de las principales causas jurídicas para el cierre de una compañía efectuado como tesis de postgrado por Palma César, Hurtado Chambert (2008), denominado Análisis de las Principales Causas que Motivaron la Disolución, Inactividad, Liquidación y Cancelación de Compañías y su Incidencia en el Ámbito Societario y Mercantil Ecuatoriano, elaborada en la Universidad Técnica Particular de Loja.

En lo administrativo, la demanda de información sobre la creación y desaparición de empresas, no deja de crecer, y es fundamental para tener la certeza 
sobre la demografía empresarial de un país, por ejemplo España es un buen ejemplo de manejo de información sobre el tema, a través de su Instituto $\mathrm{Na}$ cional de Estadísticas ${ }^{5}$. Particularmente en el Ecuador se requiere mejorar la gestión y colaboración de las empresas públicas, para así contar con información actualizada sobre los temas desarrollados en las diferentes investigaciones.

Como punto de partida sobre el tema de la mortalidad de las empresas, destacamos lo planteado por los científicos sociales, Hannan y Freeman ${ }^{6}$, autores del libro Ecología Organizacional (1993), quienes establecieron una relación entre el desarrollo de una sociedad con el desarrollo de nuevas empresas y como nacen, sobreviven y mueren. Los autores plantean que algunas organizaciones van a desaparecer de todas maneras, por mejor trabajo de alineación con el entorno que hagamos, pues responderán a un ciclo normal de vida de las empresas, en tanto que otras bajo un principio Darwiniano, si se adaptan a los nuevos cambios podrían sobrevivir. Además establecen que la muerte de las empresas depende de su edad y el tamaño, es así que las empresas nuevas por su poco conocimiento del medio y reciente desarrollo de su organización y estructura, tienen mayores probabilidades de desaparecer, a diferencia de las empresas de gran tamaño que pueden enfrentar con mayores probabilidades el riesgo de ser cerradas o eliminadas en el mercado.

Un elemento importante a considerar es que partiendo de la concepción teórica y lo que establece la actualidad tenemos que analizar el Ciclo de la vida empresarial que se ha desarrollado como aquel que los organismos vivos experimentan a cierta manera y que da como consecuencia un enómeno empresarial que determina el comienzo y fin de las operaciones de una empresa que en la legislación ecuatoriana actual vigente es determinado por el organismo de control y vigilancia empresarial.

$\mathrm{Al}$ analizar las causas que internamente inciden en el Ciclo de vida empresarial para el fracaso de todos los emprendimientos y las nuevas ideas de negocio podemos determinar las siguientes:

Etapa empresarial o nacimiento, cuando una organización nace en la mente de los emprendedores la principal característica es la presencia familiar y de alguna manera se pone énfasis en la creación de un producto o un servicio, y su supervivencia en el mercado y tratar de hacerse notar en el mismo. La relación de éxito que otras personas tuvieron en el sector en el cual se quiere emprender es el principal estudio e investigación de mercado para determinar la gestión a seguir en la nueva empresa.

5 En el año 2011, en España operaron 3’514.894 empresas, se crearon 287.780 y desaparecieron 332.114. La tasa neta entre nacimientos y muertes de empresas fue del 1,3\%, frente al - 0,9\% del año 2'010.

6 Michael T. Hannan, Profesor of Sociology en la Universidad de Stanford y John Freeman, Profesor de la Graduate School of Management en la Universidad Cornell. 
En la medida que una organización empieza a crecer, los problemas de carácter administrativos lo hacen de tal manera que uno de los principales es el mayor número de empleados genera problemas. Las dificultades parten del cumplimiento de todas las regulaciones tanto de tipo local, provincial y nacional que hacen que el emprendedor sienta cierto tipo de frustración al verse involucrado procesos burocráticos.

En referencia a tiempo y momento podemos decir que este es un proceso que va marcado por un largo periodo de tiempo, de hecho, podemos decir que las empresas pueden pasar al siguiente momento empresarial a partir del tercer año de actividades pudiendo ser más o menores los tiempos que son determinados por resistencia y perseverancia.

En la Etapa de colectividad y desarrollo, si se resuelve la crisis y teniendo en cuenta el liderazgo, la organización comienza a desarrollar objetivos y dirección claros. Se establecen por primera vez autoridad, jerarquía y definiciones de puestos de trabajo. A raíz de lo mencionado anteriormente los empleados nacen las primeras nociones de identificación con la misión de la organización y pasan largas horas ayudándola a tener éxito. Aunque la organización empieza a estar estructurada formalmente, aun retiene un aire de informalidad y flexibilidad muy bien marcados. Los dueños pasan a delegar responsabilidades a los empleados de los niveles más básicos; en esta etapa según datos del organismo de control son muy pocas empresas a razón de cada diez nacimientos societarios solo tres llegan a este punto al tercer año de operaciones.

Etapa de formalización y madurez, se refiere a la instalación y uso de reglas, procedimientos y sistemas de control. La comunicación informal es menos frecuente. Nace la imagen y el posicionamiento en el medio de la empresa como referente. Las organizaciones que se encuentren en esta fase deben buscar un equilibrio entre una mayor necesidad de ampliar sus fronteras y una necesidad continua de ser flexibles y sensibles a las condiciones cambiantes del entorno. El periodo de tiempo para llegar a esta consolidación empresarial será mayor a los quince años de sobrevivencia en el mercado, partiendo de esta premisa y como parte de nuestra investigación tenemos a la sucesión familiar como parte de la mortalidad empresarial.

Etapa de elaboración y decadencia, después de que la organización alcanza su madurez, puede entrar en periodos de declinación temporal. Puede ser necesaria una renovación cada 10 o 20 años. La organización se desalinea del entorno o tal vez se hace lenta y sobre burocratizada y debe pasar por una etapa de adelgazamiento e innovación. La reinversión y la consolidación de un nuevo norte empresarial marcaran la vida o no de las empresas.

Como inicio y partiendo de nuestro análisis tenemos a la administración empírica, que es la administración cuyos fundamentos son una orientación a la experiencia personal, donde la práctica y la experiencia pesan mucho más que la teoría para su aprendizaje y ejecución. Los estudios relacionados con estos pensamientos se centran en la observación directa de lo que funciona en 
las empresas actualmente. Son múltiples los factores que afectan y determinan una situación de crisis empresarial, el organismo de control en el Ecuador no presenta las causas reales de muerte empresarial ya que en la Ley de Compañías vigente muestra los pasos para disolver, liquidar y cancelar las compañías con un reglamento muy estricto por seguir pero sin llegar al detalle a manera de prevenir a futuro todos los problemas que llevaron a su extinción.

En el ámbito contable/ financiero encontramos dos autores de nacionalidad colombiana y un autor argentino que hacen referencia a la temática de la presente investigación. En, Bedoya Humberto (2014), se presenta al lector información sobre las 10 principales causas de muerte empresarial desde el punto de vista contable/financiero, contemplando entre ellas: Financiar un activo fijo con un crédito a corto plazo; No cuadrar los plazos de compra con los de venta. Según, Farfán Buitrago Yolima (2014) en su material "Vida y Muerte Empresarial, ESTUDIOS EMPIRICOS DE PERDURABILIDAD", presenta al lector la información de las causas que originaron el cierre de las empresas en Bogotá en el periodo 2006-2008 identificando los siguientes factores: Falta de capacidad para Atender el mercado internacional ${ }_{i}$ Escaso conocimiento

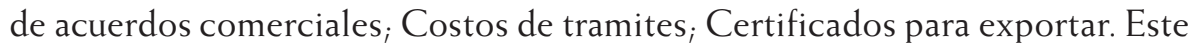
trabajo tiene por objetivo principal servir como un elemento de prevención para todos aquellos que son propietarios o pretenden emprender en nuevos proyectos empresariales entre otras las causas de criterio contable / financiero que cita el autor son: Mal manejo de inventarios ${ }_{i}$ Excesiva inversión en activos fijos; $_{i}$ Falencias en materia de crédito y cobranzas; Fallas en controles internos; Mala gestión financiera en materia de endeudamiento y liquidez, Lefcobich Mauricio (2014), en su obra Las Empresas y las Causas de sus Fracasos.

\subsection{Resultados De LA INVESTIGACIÓN}

Se lograron obtener los siguientes resultados:

\subsubsection{Cuantificación del fenómeno de disolución, liquidación y cancelación de compañías de comercio}

En base a información sobre Estadísticas del Sector Societario (2013), publicadas por la Superintendencia de Compañías del Ecuador, conocemos que en el año 2013, se disolvieron 7.467 empresas a nivel nacional, en el año 2014 se disolvieron 3.139 empresas; $y$, de forma consolidada, desde enero del 2012 hasta mayo de 2014, se han disuelto, liquidado y cancelado 17314 compañías a nivel nacional. Desde inicios de julio 2014, 5.400 empresas han sido notificadas, por haber incurrido en alguna causal de disolución. La Superintendencia de Compañías, ha notificado a las primeras 730 empresas que están inmersas en causal de disolución desde hace dos años. Finalmente, la entidad de control ha informado que, para ejecutar esta tarea con las 5.400 empresas notificadas, 
tiene planificado analizar y disolver las mismas por grupos, en una cifra de 600 empresas por mes aproximadamente ${ }^{7}$.

Respecto a la Región Central del país, la misma fuente señala que para el año 2013 existían 1770 compañías de comercio, de las cuales aproximadamente un $30 \%$ se encontraban inmersas en diversos procesos de disolución, liquidación y cancelación, es decir, de alguna manera se encontraban dentro de procesos que las conducían a una "mortalidad societaria". La información citada, nos da una idea clara de la magnitud del problema. Es importante destacar que, la información oficial presentada no permite conocer las reales causas detrás del inicio de procesos de inactividad, disolución, liquidación y cancelación de estas compañías, debido a la aplicación del principio de confidencialidad de la información, el cual guarda las misma buscando proteger los derechos de las sociedades inmersas en estos procesos (siendo esto necesario por el respeto a los derechos de las personas y la seguridad jurídica en el país). Sin embargo, es precisamente esta misma reserva la que no ha permitido disponer de mayor información oficial respecto de las causas de mortalidad de las compañías, razón por la cual el proyecto tuvo que hacerlo de primera mano, mediante entrevistas en profundidad a referentes expertos de opinión en el tema (del sector público y privado), logrando recaudar información que nos condujo a conocer en mayor detalle las causas que originan la muerte de las compañías.

\subsubsection{Análisis de la normativa ecuatoriana pertinente}

Oficialmente la Superintendencia de Compañías del Ecuador, a través de su máxima autoridad, ha proporcionado una idea general de las causas por las cuales estas compañías han entrado en este proceso, al decir que las empresas notificadas "... tenían pérdidas, no han declarado ingresos o han declarado muy poco. 1500 presentaron descargos, pero en ciertos casos fueron insuficientes, otras van a aumentar el capital y algunas pidieron la disolución voluntaria...". Dentro de la normativa jurídica ecuatoriana, la mortalidad de las compañías se manifiesta a través de la ejecución del proceso de inactividad, disolución, liquidación y cancelación de compañías contemplado en la Ley de Compañías vigente en Ecuador. Los elementos de este proceso, trabajan en conjunto y de forma secuencial (ver Gráfico 1).

El proceso inicia con la Inactividad, consistente en la declaratoria de inactividad efectuada por la Superintendencia de Compañías, a petición de parte o de oficio, a aquellas compañías sujetas a su control y que no hubieren operado durante dos años consecutivos, presumiendo esta inactividad cuando la empresa no hubiere cumplido, en tal lapso, con lo dispuesto en el Art. 20 de la

7 Información proporcionada por la Superintendencia de Compañías, a diario El Comercio de Quito, la cual fue publicada el Miércoles 27 agosto 2014. 
Ley de Compañías (ver Nota 3). El segundo elemento es la Disolución, la cual para Reyes (2008): "es el acto jurídico que implica, frente a socios y a terceros, que el ente societario ha terminado su fase activa vinculada a la producción y está próximo a iniciar su etapa de extinción total y definitiva" (p. 38). Legalmente, la disolución implica el final de la plenitud jurídica de la compañía, la resolución de las relaciones vinculantes en que sea sujeto y la cesación de las actividades comprendidas en su objetivo social. La causa que subyace para dar por terminado el vínculo societario entre sus integrantes, es la extinción de la affectio societatis entre ellos (ver Nota 4), institución del Derecho Romano que representa la voluntad de asociarse que tuvieron los socios al fundar la compañía, estando dispuestos a trabajar juntos y, permanecer juntos en el emprésito (V.gr. con el ánimo de formar sociedad). Es importante observar que, a pesar de que se da la resolución del negocio social (entre los socios), esto no significa la extinción de la persona moral nacida de él, pues ésta (la compañía), aunque pierde su capacidad para realizar nuevas operaciones, subsiste para efectos de resolver, en una etapa posterior llamada liquidación, los vínculos jurídicos establecidos entre la sociedad con terceros; ${ }_{i}$ con sus socios; $y_{\text {, }}$ por los socios entre sí. En nuestra normativa jurídica, existen dos fuentes principales que originan la disolución de una compañía: i) por causales establecidas en la Ley; y, ii) por voluntad de los socios o accionistas.

Respecto a la primera posibilidad, a su vez, la normativa nacional prevé trece posibles causales para ejecutar esta disolución, siendo la más común de ellas, el incumplimiento durante cinco años de la obligación de enviar, a la entidad de control, durante el primer cuatrimestre de cada año, cierta documentación que evidencia su normal accionar. Dentro del mismo primer numeral, la Ley también contempla la "disolución de pleno derecho"(ver Nota 5), la cual no requiere de declaratoria, ni de publicación, ni inscripción, remitiéndose a las causales establecidas en el Art. 361 de la Ley de Compañías (codificación 1999), el cual contiene 13 causales para que se ejecute la disolución de una compañía de comercio. Respecto a la segunda posibilidad, la disolución por voluntad de los socios / accionistas, se ejecuta mediante el Trámite Abreviado de Disolución y Cancelación Voluntaria y Anticipada y Petición de Cancelación de una compañía de comercio, contemplada en el respectivo Reglamento emitido por la Superintendencia de Compañías" (ver Nota 6). Finalmente, también existen ciertas causales especiales para este efecto, aplicables solamente a las compañías en nombre colectivo, en comandita simple, en comandita por acciones; y, de responsabilidad limitada (ver Nota 7).

El tercer elemento del procedimiento, la Liquidación, según Gómez Rondón (2002), representa "la real terminación de los negocios de la empresa, el pago de sus obligaciones y si hubiere algún remanente de sus activos, se distribuirán entre los socios" (p, 90). Según el Art. 377 de la Ley de Compañías (codificación 1999), una vez "disuelta la compañía se pondrá en liquidación, excepto en los casos de fusión y escisión" (p. 73). La compañía en liquidación 
requiere conservar su personalidad jurídica (vida jurídica) mientras se desarrolla este proceso y hasta la cancelación, con el objeto de garantizar la debida y legal liquidación de todo el activo, pasivo y patrimonio, evitando posibles afectaciones a la misma compañía, al Estado y a terceros (ver Nota 8). Dos elementos adicionales e indispensables para la liquidación de una sociedad mercantil, son: i) el procedimiento de liquidación establecido en la Ley, (ver Nota 9); y, la designación y establecimiento de funciones del liquidador de la compañía (ver Nota 10). Previo a que se ejecute el paso final de cancelación, es posible ejecutar la Reactivación de la compañía, que significa el darle una segunda oportunidad de vida a la sociedad mercantil, basado en el hecho de aún existe affectio societatis entre los socios o accionistas, pero por supuesto, observando para ello los parámetros determinados en la propia Ley (ver Nota 11).

Finalmente, respecto al tercer elemento del procedimiento, la Cancelación, entendamos la misma como el paso final para la muerte de una compañía, cancelando la inscripción de la compañía en el Registro Mercantil. Al respecto, el Art. 404 de la Ley de Compañías (codificación 1999), dispone que "Concluido el proceso de liquidación, en cualquiera de las formas previstas en los artículos anteriores, a pedido de liquidador, el Superintendente de Compañías dictará una resolución ordenando la cancelación de la inscripción de la compañía en el Registro Mercantil" ( p. 79).

Es importante indicar que, una vez iniciado el proceso, la prosecución de sus cuatro etapas está secuencialmente concatenada hasta provocar la muerte de la compañía, pudiendo solamente existir tres opciones de detener este procedimiento: i) por reactivación ordenada por la entidad de control, ii) por reactivación voluntaria acordada por los socios o accionistas; y, iii) por dejar en abandono el procedimiento, lo cual a pesar de ser una práctica común, realmente no constituye una remediación legal ni efectiva para evitar que sobrevenga la muerte de la compañía con el paso del tiempo. Es necesario mencionar que nuestra normativa jurídica contempla otras formas de extinción de una compañía mercantil, como son los procedimientos de transformación, fusión y escisión de compañías, los cuales permiten que una compañía deje de existir como persona jurídica, aunque sus diversos activos, pasivos y patrimonio, puedan seguir existiendo como parte integrante de otras compañías (ver Nota 12). 


\section{GRÁFICO 1}

PROCEDIMIENTO DE DISOLUCIÓN, LIQUIDACIÓN Y CANCELACIÓN

\section{DE COMPAÑÍAS, VIGENTE EN ECUADOR}

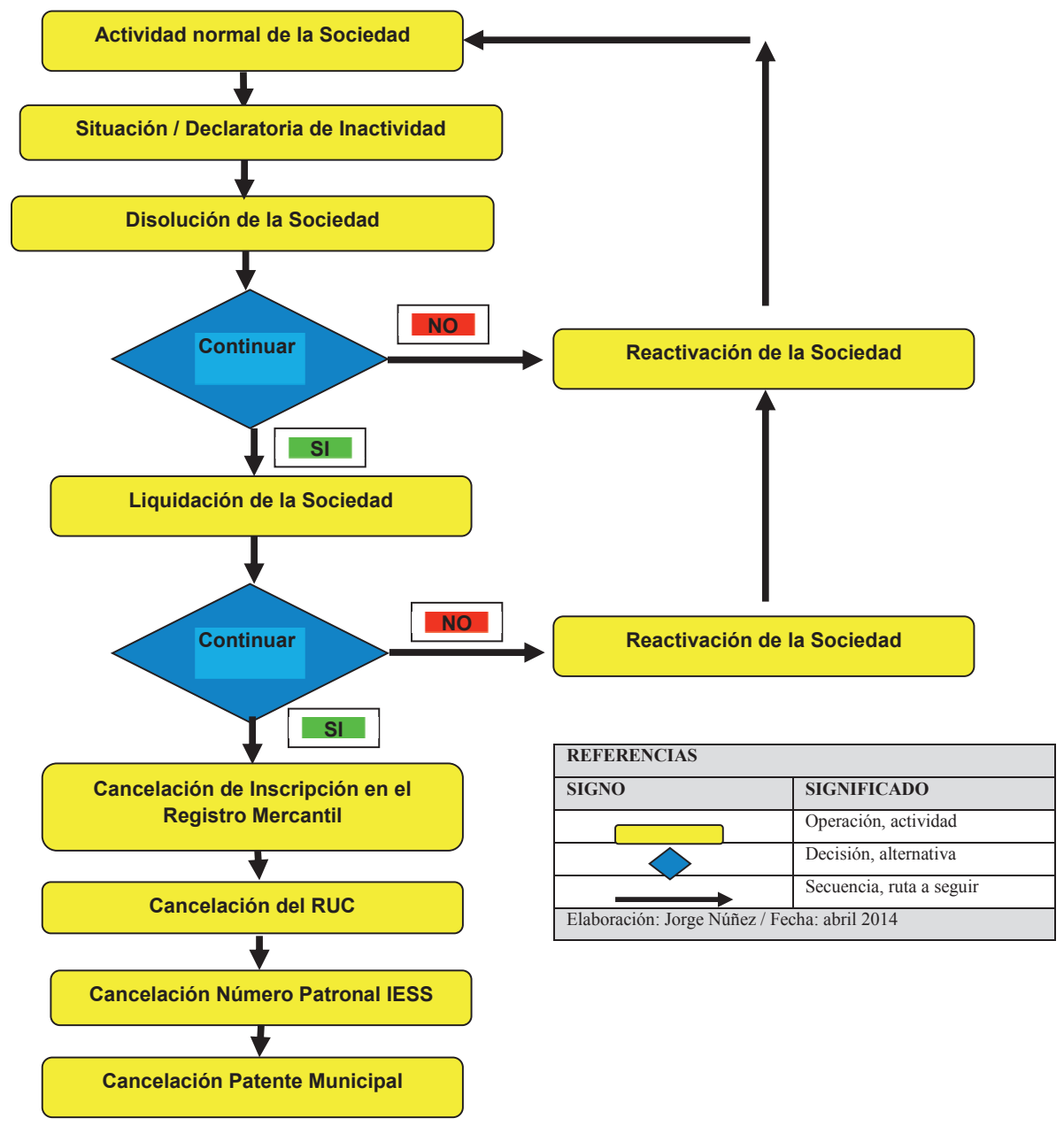

Como resultado final de este análisis jurídico y, en base a las entrevistas en profundidad a referentes de opinión experta, se determinaron que las dos principales causas para que las compañías de comercio cierren, tienen relación con:

Incumplimiento de la normativa legal, lo que desencadena acciones de pleno derecho de parte de la Superintendencia de Compañías contra la sociedad mercantil infractora, declarándola el disolución, liquidación y cancelación ${ }_{i} y_{\text {, }}$ La decisión voluntaria de los socios o accionistas, de cerrar la compañía, ingresando voluntariamente al proceso de disolución, liquidación y cancelación de la misma. 


\subsection{3 Ámbito administrativo}

En la presente investigación, se analizó las causas de mortalidad de las empresas de la región centro del país ${ }^{8}$, que desde el punto de vista administrativo pueden existir al momento. Siendo las principales causas las siguientes:

Es importante destacar el entorno de la presente investigación. En los últimos cinco años, el país desarrolla un proceso de cambio en su modelo de crecimiento lo cual indudablemente influenciará en el mapa empresarial, siendo un punto a destacar el cambio de la matriz productiva que busca potenciar nuevas empresas de valor agregado. Por lo tanto, las empresas que no asuman esta nueva realidad, perderían competitividad tanto a nivel nacional como internacional, lo cual puede implicar su desaparición en el futuro.

Una de las causas para que una empresa deje de existir, es la deficiente gestión gerencial de las empresas, los niveles directivos tienen debilidades en su formación profesional y experiencia, con una tendencia al empirismo. $\mathrm{Pa}$ ra la toma de decisiones en las empresas, no se usan herramientas de gestión organizacional modernas, como sistemas de calidad, sistemas de evaluación, gestión por procesos, estudios de mercado, entre otros. La capacitación y formación del personal en las empresas es deficiente, limitada por temas presupuestarios o falta de interés en desarrollar procesos de formación continua, lo cual afecta la productividad de la misma. Existe una débil planificación de la capacitación del personal de las empresas, por lo que a veces se realizan actividades aisladas sobre este tema.

Desde la constitución misma de las empresas, el espíritu empresarial inicial se ve desplazado por el interés de generar ganancias y rentabilidad inmediata, únicamente. Además, la realidad de las empresas familiares de la región, donde prima la informalidad, siendo el criterio técnico subordinado a las relaciones de parentesco ${ }^{9}$. Además no siempre existe quien tome la posta en el cambio generacional de la empresa familiar, donde algunas no pasan de la primera generación.

La planificación empresarial es débil, se la realiza y no se aplica, y en algunos casos es casi nula, por lo que la toma de decisiones y la gestión diaria se da por impulso y las circunstancias del momento. Por ejemplo: los pronósticos de ventas iniciales no se cumplen, porque fueron mal elaborados o no se aplicó la

8 El emprendimiento y desarrollo empresarial es un referente de la región centro del país, es así que 23 compañías de Tungurahua, Cotopaxi y Chimborazo, se encuentran entre las más importantes del país, según el Ranking general de la Superintendencia de Compañías

9 "El paso de la primera a la segunda generación es sumamente delicado, y una prueba de ello es que los dos tercios de las empresas familiares no sobreviven a la primera generación". Tesis Modelo de Gestión Administrativa para la Transición de la Primera a la Segunda Generación en las Empresas Familiares Ecuatorianas, Yadira Fernanda Acurio Cantuña, 2010 
estrategia de marketing correcta. Planes de negocio mal elaborados o que no se cumplen. No se cuentan con planes de marketing técnicamente elaborados.

Las empresas tienden a estancarse, al no integrar la Innovación como parte de su cultura organizacional, se conforman con lo necesario y no arriesgan dar un paso delante de lo que se acostumbran hacer, es así que se requiere desarrollar los estándares de calidad en la producción nacional y en los servicios prestados, a fin de ser más competitivos.

La flexibilidad y capacidad de respuesta ante el cambio es limitada, lo que se relaciona con la falta Visión de los gerentes. El nivel directivo de las empresas tiene la tendencia a gestionar el momento y no se proyectan a futuro. Existe desconocimiento del mercado, y por ende las políticas de comercialización no son efectivas y a veces erradas, lo que genera que los planes de venta no se cumplan.

Otra de las causas citadas son las políticas del Gobierno, referentes a los varios impuestos creados, políticas arancelarias, legislación laboral poco flexible, y competencia desleal en la gestión de precios bajos, lo que puede generar complicaciones en las empresas que no participan de estas prácticas.

\subsection{4 Ámbito contable-financiero}

El cese de actividad en las empresas, tienen como elemento central el proceso de toma de decisiones, ${ }_{i}$ Es importante considerar desde esta perspectiva que la principal herramienta que sirve a la gerencia y directiva de las compañías para decidir, son los Estados Financieros ${ }^{10}$ ya que sobre los resultados que estos generen se toma las decisiones de las cuales dependerá el giro de la empresa y el futuro de sus socios o accionistas.

Por lo antes mencionado es importante exponer las ventajas y aplicaciones del Análisis de la situación financiera incluyendo en el mismo ratios ${ }^{11} \mathrm{o}$ índices que permitan conocer el estado real de la empresa. Entre los Índices Financieros que más soporte dan se puede destacar:

Ratio de liquidez general o razón corriente:

$$
\text { LIQUIDEZ GENERAL }=\frac{(\text { ACTIVO CORRIENTE })}{\text { (PASIVO CORRIENTE })}
$$

10 En este artículo se usa el concepto de Estado Financiero, siguiendo la postura teórica de Fuente especificada no válida. quien manifiesta que: Los estados financieros constituyen una representación estructurada de la situación financiera y del desempeño financiero de una entidad; Son informes que se preparan a partir de los datos de los registros contables, y presentan diversos aspectos de la situación financiera, resultados y flujos de efectivo de una empresa, de conformidad con los Principios de Contabilidad Generalmente Aceptados.

11 Matemáticamente un ratio es una razón, es decir, la relación entre dos números. Son un conjunto de índices, resultado de relacionar dos cuentas del Balance o del Estado de Resultados Integral. Los ratios proveen información que permite tomar decisiones acertadas a quienes estén interesados en la empresa. 
Es el índice más utilizado para demostrar la liquidez de una empresa ${ }_{i}$ en otros términos relaciona en que porcentaje el activo corriente cubre la deuda a corto plazo.

Ratio capital de trabajo:

\section{CAPITAL DE TRABAJO $=$ ACTIVO CORRIENTE - PASIVO CORRIENTE}

A través de este índice la empresa verifica el valor real con el que cuenta para el desempeño de sus operaciones cotidianas una vez que ha cubierto todas sus obligaciones.

Los hallazgos encontrados dentro del campo contable financiero hacen referencia a falencias como: Financiar un activo fijo con un crédito a corto

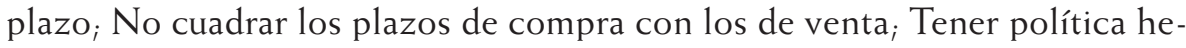
rrada de descuentos ${ }_{i}$ La tasa interna de retorno es menor que el capital ${ }^{12}{ }_{i}$ No aumentar facturación en mayor proporción que costos y gastos.

Además; Mal manejo de inventarios; Excesiva inversión en activos fijos; Falencias en materia de crédito y cobranzas; ${ }_{i}$ Fallas en controles internos; Mala gestión de fondos ${ }_{i}$ Incumplimiento de obligaciones impositivas y laborales.

Las observaciones que se obtuvo a cerca de las principales causas según el criterio de expertos tanto en el sector público como en el privado, se detallan a continuación:

Las empresas consideran un gasto injustificado el contratar un contador de planta para su empresa; y optan por los servicios empíricos que oferta un informal ${ }_{i}$ Algunos profesionales de la contabilidad no desempeñan de manera ética y correcta su trabajo.

El gerente no se involucra en el cumplimiento de las obligaciones tributarias y oculta información importante al contador; Ausencia de cultura y moral tributaria, Las empresas no manejan flujos de efectivo; Deficiente análisis e interpretación de los estados financieros; Gastos financieros excesivos; Sobreendeudamiento; La contabilidad dentro de la empresa no es considerada como un herramienta, sino más bien como una imposición, No existe cultura de cumplimiento tanto laboral como tributario; Carga laboral y tributaria muy fuerte para los empresarios; Considerando que del 100\% de las utilidades obtenidas, de ser el caso, el 15\% se deberá destinar para repartición a los trabajadores y el $22 \%$ para Impuestos y esto sin considerar el anticipo de Impuesto a la renta ${ }_{i}$ No se establecen costos reales de producción aplicando una acertada contabilidad de costos.

Los resultados obtenidos en la presente investigación mantienen similitud entre los diferentes criterios consultados; lo cual ratifica que desde la perspectiva contable las empresas cesan sus funciones por el desconocimiento de

12 Las tasas internas de retorno se utilizan habitualmente para evaluar la conveniencia de las inversiones o proyectos. 
quienes están frente a su manejo de la importancia de manejar un acertado sistema financiero que permita mantener un control adecuado de todos y cada uno de los movimientos y transacciones que la entidad realiza; si bien es cierto la contabilidad es un conjunto de procesos que permiten analizar, clasificar, registrar, controlar e interpretar las operaciones que una empresa efectúa en su diaria labor; el producto final de este proceso son los Estados Financieros y estos a su vez constituyen la herramienta principal para la toma de decisiones. Esto se ilustra en el Gráfico 2.

Un común denominador entre los criterios expertos sugeridos en el estudio, es la, ausencia de cultura y moral tributaria.

El Estado en busca de generar cultura tributaria en los ciudadanos ha realizado una importante inversión tanto en publicidad como en capacitaciones para lograr el objetivo en mención; Sin embargo aun cuando es evidente que la administración tributaria a través del Servicio de Rentas Internas ha logrado en los últimos años un record en recaudación, cabe analizar si se logró concientizar al empresario de la importancia de pagar a tiempo y con transparencia sus impuestos o es el sistema castigador el que obliga a cumplir con los tributos?

Establecer costos en el caso de la empresa industrial:

Partiendo del concepto que cataloga como empresa industrial a aquella que transforma materia prima en producto terminado a través de un proceso de fabricación o producción, Evidentemente el no manejar el costo real del producto podría desencadenar en un cierre de la empresa, claro si el fin de la entidad es obtener lucro lo primero que deberá hacer es llegar al costo exacto del producto, para lo cual es necesario asignarle el valor correcto a cada proceso hasta obtener el costo final, y sobre este valor cargar la utilidad requerida para obtener el precio de venta; ${ }_{i}$ para solventar este cálculo es necesaria la aplicación de Contabilidad de costos; nuevamente la Contabilidad como herramienta para el manejo optimo y eficiente de los recursos de una empresa.

Manejar un proceso contable adecuado permite conocer la realidad económica y financiera de la empresa ${ }_{i}$ anticiparse a situaciones difíciles y prever oportunidades. 


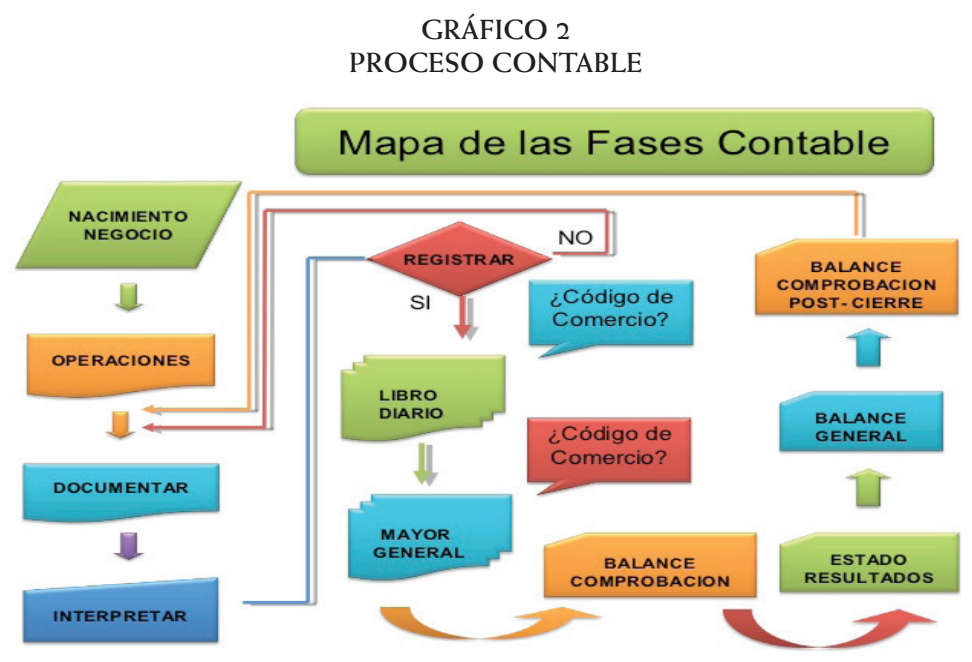

Elaborado por: Verónica Peñaloza

\section{ANÁLISIS COMPARADO DE LA SITUACIÓN PERTINENTE EN COLOMBIA Y PERÚ}

En lo jurídico, la principal diferencia radica que en Colombia, no existe una ley especializada en el tratamiento del campo societario, siendo el Código de Comercio, en su Libro II De las Sociedades Comerciales, el que se ocupa de normar esta materia. Por otra parte, una de las principales similitudes encontradas es que en los dos países, existen órganos públicos de control societario autónomos, a manera de superintendencias, así, en Colombia funciona la $\mathrm{Su}$ perintendencia de Sociedades y, en Ecuador la Superintendencia de Compañías. Al respecto del procedimiento en estudio, es importante comentar que entre las normativas colombiana y ecuatoriana, existen más similitudes que diferencias dentro del procedimiento administrativo en estudio $;$ al respecto de las diferencias solamente de forma, por lo que los usuarios y operadores de justicia de ambos países podrían, en ciertas ocasiones, aplicar un análisis de derecho comparado a manera de guía para su toma de decisiones.

En lo jurídico, la principal similitud radica que en Perú, al igual que en Ecuador, existe una ley especializada en el tratamiento del campo societario; en Perú la Ley General de Sociedades y en Ecuador la Ley de Compañías. Otra de las similitudes encontradas es que en los dos países, existen órganos públicos de control societario autónomos, a manera de superintendencias; así, en Perú

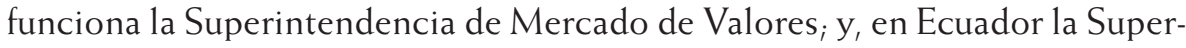
intendencia de Compañías. La principal diferencia encontrada, radica en que en la legislación peruana, no se estipula como causal de disolución el traslado del domicilio principal a país extranjero, tal como si lo señala el núm. 2. del Art. 361 de la Ley de Compañías de Ecuador. Al respecto del procedimiento 
en estudio, es importante comentar que de forma similar que lo ocurrido con Colombia, entre las normativas peruana y ecuatoriana, existen más similitudes que diferencias dentro del procedimiento administrativo en estudio ${ }_{i}$ al respecto de las diferencias solamente de forma, por lo que los usuarios y operadores de justicia de ambos países podrían, en ciertas ocasiones, aplicar un análisis de derecho comparado a manera de guía para su toma de decisiones.

En lo administrativo, la realidad histórica y socio-cultural, y económica, tanto colombiana como peruana es similar a la ecuatoriana, por lo que en la gestión administrativa de sus empresas hay semejanzas, claro está considerando que los tamaños de mercados y población son muy diferentes. En os tres países, el tejido empresarial en la mayoría son PYMES, frente a la gran empresa, siendo las causas similares a lo que sucede en el Ecuador. La falta de capital e innovación se destacan.

En lo Contable-Financiero, según el presidente de Confecámaras de Colombia, (Dominguez), "el riesgo de mantener empresas en la informalidad, es decir, sin adquirir un registro mercantil, tributar y pagar prestaciones sociales, es que el promedio de vida de una empresa no superará los 3 años; Negocios de pequeña escala e informales no tienen capacidad de crecer, no tienen acceso de distribución, no tienen acceso al crédito, no tienen acceso a seguridad social y en consecuencia es muy difícil que crezcan, entonces caen en una trampa de existencia que hace que sucumban en un promedio de tres años".

\section{ANÁLISIS DE DOS CASOS DE EJEMPLO, DE COMPAÑÍAS ECUATORIANAS CANCELADAS, EN LA REGIÓN CENTRAL DEL PAÍS}

Se analizaron dos casos de compañías de la Región Central, que fueron cerradas; las nombraremos en adelante con los nombres ficticios de: a) Compañía Distribuciones Consumo Masivo Cia.Ltda; y, b) Compañía Publicitaria Cia. Ltda, con el propósito de cuidar su identidad e imagen.

Respecto a la primera, Compañía Distribuciones Consumo Masivo Cia.Ltda.; sucede que la Superintendencia de Compañías, resolvió solicitar la cancelación de la inscripción de la misma en el Registro Mercantil, por haber incurrido en la causal dispuesta en el inciso segundo del Art. 405 de la codificación de la Ley de Compañías, que indica que el Superintendente de Compañías podrá solicitar la misma, de las compañías que no hubieren terminado el trámite de disolución y liquidación en el lapso de un año contado desde la expedición de la resolución de disolución. Es decir, esta compañía se cancela por incumplimiento de la Ley. Respecto a la segunda, Compañía Publicitaria Cia. Ltda., sucedió un caso similar a la primera, es decir, entró o en causal de disolución, liquidación y cancelación debido a incumplimiento de la Ley. 


\section{METODOLOGÍA}

Se aplicaron los métodos exploratorio y descriptivo. En el primero de estos, se aplicó a manera de instrumento de campo la entrevista en profundidad, relevando información de diversos referentes expertos de opinión (ver Nota 2), pertenecientes a entidades tales como: Corte Nacional de Justicia, Dirección Regional del SRI, Intendencia Regional de Compañías, Presidencia y Direcciones Ejecutivas de las Cámaras de Industria y Comercio de Tungurahua, Cotopaxi y Chimborazo, Colegio de Contadores de Tungurahua y Academia Ecuatoriana de Derecho Societario. Respecto al método descriptivo, se lo utilizó para relacionar los hallazgos del estudio, con cada uno de los objetivos planteados.

\section{CONCLUSIONES}

Se concluye que, las principales causas para el cierre de compañías en la Región Central de Ecuador, tienen relación con:

El incumplimiento de la Ley por parte de las compañías de comercio y sus integrantes, sea por desconocimiento o por inadecuada gestión empresarial, lo que genera las acciones de oficio que toma la Superintendencia de Compañías, aplicando el procedimiento de disolución, liquidación y cancelación establecido en la Ley.

La pérdida de la Affectio Societatis entre los integrantes de una sociedad mercantil, lo cual se traduce en la decisión voluntaria de disolver el vínculo societario entre socios y por tanto la compañía, es la principal causa para la muerte de las compañías de comercio.

La gestión administrativa y gerencial de las empresas mercantiles de la región centro del país, requiere el fortalecimiento técnico y profesional de su nivel directivo, a fin de garantizar su competitividad y proyección a futuro, y evitar que desaparezcan del mercado. En particular, existe una débil planificación empresarial y manejo de información de la demografía empresarial.

Informalidad de las empresas familiares de la región, que incide en la toma de decisiones.

No se utiliza la Contabilidad como herramienta para el manejo óptimo y eficiente de los recursos de la empresa ${ }_{i}$ más bien se considera una imposición por lo tanto no existe análisis e interpretación de resultados.

Ausencia de cultura y moral tributaria por parte de los empresarios.

El equipo de investigación agradece el aporte y colaboración recibida para el presente estudio, de las siguientes instituciones: Corte Nacional de Justicia del Ecuador, Superintendencia de Compañías, Servicio de Rentas Internas, Cámara de Industrias de Tungurahua, Cámara de Comercio de Ambato, Cámara de Industrias de Chimborazo, Cámara de Comercio de Latacunga, Colegio de Contadores de Tungurahua, Academia Ecuatoriana de Derecho Societario. 


\section{REFERENCIAS}

Bedoya, Humberto. (2014) Gerencia de Cambio, 10 Causas de muerte empresarial http://www.degerencia.com/articulo/10_causas_de_muerte_empresarial

Cámara de Industrias y Producción de Pichincha. (2011). La carga tributaria en el Ecuador. Quito-Ecuador. Editorial Pantone.

Congreso Nacional del Ecuador, Codificación de la Ley de Compañías. (1999). Quito-Ecuador.

Consejo de Estado de la República de Colombia, Código de Comercio (1971), Arts. del 218 al 224; Arts. del 225 al 259; Arts. del 457 al 460. Bogotá, Colombia.

Congreso de la República del Perú, Ley General de Sociedades (1997); Arts. del 407 al 412; Arts. del 413 al 420; Arts. del 421 al 422. Lima, Perú.

Estadísticas del Sector Societario, Superintendencia de Compañías (2014), www. supercias.gob.ec, Quito, Ecuador.

Farfán Buitrago Yolima, (2014). Vida y muerte Empresaria. Estudios Empíricos de Perdurabilidad http://www.urosario.edu.co/urosario_files/d1/d1d6dd15-4966-4dc79f5b-e92d00acce3f.pdf

Gómez Rondón Francisco, Contabilidad III Semestre: (teoría y prácticas) (2002), Ed. Fragor, Caracas- Venezuela.

Lefcobich Mauricio. (2014). Las empresas y las causas de sus fracasos, http://www. monografias.com/trabajos16/fracasos-pequenas-empresas/fracasos-pequenasempresas.shtml

Montenegro A. (2012). Diseño de un manual de lineamientos para disminuir la mortalidad en las compañías de nueva creación en la intendencia de compañías de Ambato en la zona central del país. Ambato-Ecuador. PUCESA.

Palma César, Hurtado Chambert, Análisis de las principales causas que motivaron la disolución, inactividad, liquidación y cancelación de compañías y su incidencia en el ámbito societario y mercantil Ecuatoriano, Universidad Técnica Particular de Loja, (2008), Loja-Ecuador.

Reyes Villamizar Francisco, Disolución y Liquidación de Sociedades, (2008), Ed. Doctrina y Ley Ltda., Bogotá. 


\title{
NOTAS ADICIONALES
}

Nota 1- La normativa jurídica vigente en Ecuador, aplicable al proceso de inactividad, disolución, liquidación y cancelación de compañías, comprende principalmente: Ley Orgánica para el Fortalecimiento y Optimización del Sector Societario y Bursátil, Codificación de la Ley de Compañías de Ecuador, como normativa secundaria y de directa aplicación al tema en referencia ${ }_{i}$ Ley Reformatoria a la Ley de Compañías; Reglamento sobre inactividad, disolución, liquidación, reactivación y cancelación de las compañías anónimas, de economía mixta, en comandita por acciones y de responsabilidad limitada y cancelación del permiso de operación de sucursales de compañías extranjeras $_{i}$ Reglamento, Requisitos de Informes de Auditoría Externa a Compañías; Instructivo Societario para la constitución, aumento de capital y más actos de las compañías mercantiles sometidas al control de la Superintendencia de Compañías (2006), Quito, Ecuador.

Nota 2- El formato de entrevista aplicada a los referentes expertos de opinión, fue el siguiente:

\author{
Pontificia Universidad Católica del Ecuador \\ Sede Ambato \\ Departamento de Investigación y Postgrado \\ Proyecto de Investigación:
}

IDENTIFICACIÓN DE LAS PRINCIPALES CAUSAS DE MORTALIDAD DE LAS COMPAÑÍAS DE COMERCIO, EN LA SUB-REGIÓN SIERRA CENTRO DE ECUADOR

Agosto, 2014

Estimado/s Señor/es:

La Pontificia Universidad Católica del Ecuador Sede Ambato, se encuentra desarrollando el proyecto de investigación: "Identificación de la principales causas de mortalidad de las compañías mercantiles en la sub-región Sierra Centro, de Ecuador".

Para el efecto, solicitamos muy comedidamente a Usted/s, su colaboración proporcionando sus puntos de vista respecto a las preguntas planteadas en el presente guion de entrevista.

Es importante resaltar que toda la información recabada, será utilizada exclusivamente con $\underline{\text { fines académicos }}$; por lo que una vez haya finalizado el proyecto y se disponga de las respectivas conclusiones, compartiremos esta información con Ustedes y toda la colectividad.

\section{Guión de Entrevista:}

1. La Ley de Compañías contempla ciertas causales para declarar inactiva a una compañía; a su criterio, cuales considera Usted que son las causales que ocurren con mayor frecuencia?.

2. La Ley de Compañías contempla ciertas causales para la disolución de una compañía; a su criterio, cuales considera Usted que son las causales que ocurren con mayor frecuencia?.

3. La Ley de Compañías contempla un procedimiento para liquidar una compañía y nombrar al liquidador de la misma; en su criterio, este procedimiento es adecuado o debería modificarse? 
4. A manera de conclusión del tema tratado; cuales considera Usted que son las principales causas para la mortalidad de las compañías de comercio?

5. En base a su experiencia personal, podría dar alguna/s sugerencia/s para las actuales o futuras compañías mercantiles, a fin de evitar su mortalidad prematura?

6. Observaciones finales: comentarios abiertos y generales que desee incluir el Entrevistado.

Muchas gracias por su valiosa y gentil colaboración.

Nombre del Entrevistado:

Fecha: E-mail:

Telf.

Firma del Entrevistado:

El grupo de entrevistados, estuvo conformado por las siguientes personas:

Dr. Carlos Ramírez Romero, Presidente de la Corte Nacional de Justicia de Ecuador y, abogado especializado en materia societaria en Ecuador.

Ec. Lorena Freire, Directora del Servicio de Rentas Internas-SRI en Tungurahua, funcionaria de Estado, especializada en el campo tributario, incluyendo a las sociedades mercantiles.

Dr. César Drouet, Presidente de la Academia Ecuatoriana de Derecho Societario y, abogado especializado en materia societaria en Ecuador.

Dra. Celia Alvarez, Presidenta del Colegio de Contadores Profesionales de Tungurahua.

Ing. Carlos Andrade, Presidente del Consorcio de Cámaras de la Producción de Tungurahua y, Presidente de la Cámara de Industrias de Tungurahua.

Sr. Miguel Suárez Jaramillo, Presidente de la Cámara de Comercio de Ambato.

Sr. Luis Javier Puno, Delegado de la Directora Ejecutiva, Cámara de Comercio de Latacunga.

Ing. Federico Páez, Presidente de la Cámara de Comercio de Riobamba.

Dr. Mario Altamirano, oficina particular de liquidación de compañías.

Nota 3.- El Art. 20 de la Ley de Compañías, se refiere a la obligatoriedad que posee toda compañía de comercio en Ecuador, de enviar a la Superintendencia de Compañías, documentación que informe sobre su actividad societaria, en el primer cuatrimestre de cada año , como: "a) Copias autorizadas del balance general anual, del estado de la cuenta de pérdidas y ganancias, así como de las memorias e informes de los administradores y de los organismos de fiscalización establecidos por la Ley; b) La nómina de los administradores, representantes legales y socios o accionistas $;$ y, c) Los demás datos que se contemplaren en el reglamento expedido por la Superintendencia de Compañías.

Nota 4.- Para conocer más acerca de la institución del Derecho Romano denominada Affectio Societatis, entendida como la existencia de una comunidad de voluntades e intereses entre los socios (espíritu de colaboración entre socios), se sugiere leer a un autor clásico como Garrigues Joaquín, Tratado de 
Derecho Mercantil (1947), Ed. Revista de Derecho Mercantil, Madrid; o también a un autor neoclásico como Randazzo Salvo, The Nature of Partnership in Roman Law (2005), Australian Journal of Legal History, Sidney, Australia.

Nota 5.- El Art. 367 de la Ley de Compañías, respecto de la disolución de pleno derecho, indica en su penúltimo inciso que: ·...de esta resolución no habrá recurso alguno...", lo cual evidentemente vulnera el derecho que tenemos las personas de impugnar todos los actos administrativos emitidos por los órganos del Estado, según lo establecido en el Art. 173 de la Constitución Política vigente.

Nota 6.- El vigente Reglamento sobre inactividad, disolución, liquidación, reactivación y cancelación de las compañías anónimas, de economía mixta, en comandita por acciones y de responsabilidad limitada y cancelación del permiso de operación de sucursales de compañías extranjeras (Superintendencia de Compañías, 2013, Quito, Ecuador); contiene el procedimiento para ejecutar el Trámite Abreviado de Disolución Voluntaria, Liquidación y Solicitud de Cancelación, el cual indica el cumplimiento de los pasos procesales necesarios para efectivizarla.

Nota 7.- Al respecto, la Ley de Compañías, en sus Arts. 362, 363, 364 y 365, determina ciertas causales especiales de disolución, aplicables a las compañías

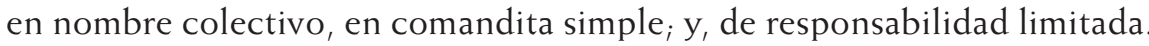

Nota 8.- Respecto de la liquidación, el Art. 378 de la Ley de Compañías, determina la conservación de la personalidad jurídica de la compañía en el proceso de liquidación, la cual debe seguir operando hasta su efectiva cancelación.

Nota 9.- Respecto al procedimiento de liquidación de una compañía de comercio, la Ley de Compañías contempla el procedimiento completo para el efecto, en sus Arts. del 392 al 401.

Nota 10.- Respecto a la designación del liquidador de la compañía, el Art. 384 de la Ley de Compañías dispone los requisitos para ser liquidador de compañías. Las funciones del liquidador de una compañía, están definidas expresamente en el Art. 387 de la misma Ley.

Nota 11.- La Superintendencia de Compañías, mediante la Resolución No. SC.IJ.DJDL.G.09.007, publicada en el Registro Oficial 110, de fecha 18 enero 2010, actualizó los requisitos para la cancelación de compañías a partir de esta citada fecha.

Nota 12.- Al respecto y, con el propósito de complementar al procedimiento principal analizado en la presente obra, mencionaré que la Ley de Compañías contempla otras opciones para extinguir una compañía, los cuales son los de transformación, fusión y escisión de compañías. 